\title{
Wind-driven stand-alone DFIG with battery and pumped hydro storage system
}

\author{
K NAVIN SAM, N KUMARESAN* and N AMMASAI GOUNDEN \\ Department of Electrical and Electronics Engineering, National Institute of Technology, Tiruchirappalli, \\ Tiruchirappalli 620 015, India \\ e-mail: nkumar@nitt.edu
}

MS received 6 November 2015; revised 23 April 2016; accepted 3 October 2016

\begin{abstract}
A wind-driven doubly fed induction generator (DFIG) along with the battery and pumped hydro storage plant (PHSP) has been devised for supplying isolated loads. PHSP-based storage system is economical and viable for the MW level wind-turbine system. The proposed scheme employs a squirrel-cage induction machine (SCIM) coupled with reversible pump turbine for PHSP. The battery storage is also included in this system to cope up with the intermittent nature of wind and fast-changing load. A simple control strategy has been implemented for maintaining the set values of voltage magnitude and frequency at the stator terminals of DFIG, which serve as a virtual grid for connecting ac loads and SCIM. Based on the availability of power in the wind, PHSP and battery, various operating modes of the proposed system have been clearly identified for supplying the isolated loads. These operating modes are clearly demonstrated through the analysis developed for this purpose and validated through experimental results. The salient features of the proposed system over the existing stand-alone wind-driven generators are (i) structural simplicity, i.e., employing only one power electronic converter, (ii) wide speed operation of wind-driven DFIG, (iii) reduced battery capacity, (iv) high energy storage using PHSP and (v) availability of continuous power to the isolated loads.
\end{abstract}

Keywords. Renewable energy electric conversion system; induction generators; wind power generation; energy storage; power converters.

\section{Introduction}

As a result of sustainable development initiatives adopted by several countries in recent years, the global renewable energy generation capacity has jumped to a record level. In the year 2013, this installed capacity accounted for more than $8 \%$, which is more than $56 \%$ of net additions to global power capacity [1]. Further, renewables meet almost onefifth of world's final energy consumption [1]. In this context, wind energy is one of the fastest growing renewable energy sources. In the year 2014, 51,477 MW of new wind energy electric conversion systems (WEECS) were installed globally [2]. The average annual growth rate of WEECS installation is around 30\% during last 10 years. For such WEECS, several electrical generators along with power converter topologies have been developed for supplying either to grid or isolated loads [3-7].

To alleviate the intermittent nature of wind, various authors have suggested integrating the energy storage devices with stand-alone WEECS [3, 8-18]. Owing to wide availability, fast response, simple power converter topologies and ease of control and management, battery storage

*For correspondence systems are popular with such small scale stand-alone wind-generator systems [3]. The size of batteries should be increased with the increase in power generation capacity for supplying continuous power to the isolated loads. Further, inclusion of battery increases the cost and also the battery has to be periodically replaced. In this regard, Kaldellis et al [19] have made a techno-economic comparison on various energy storage systems to be operated with renewable energy sources. This study shows that a pumped hydro storage plant (PHSP) is a more economical and optimal solution for big size isolated systems. Hence, PHSP is viewed as the most suitable technology in MW capacity system supplied from renewable energy sources $[16,17,19]$. As the flow control in PHSP has slow response time, additionally fast-acting storage devices, such as batteries, should be included with stand-alone WEECS for fast-changing load transients as well as wind [15].

Al-Bahrani and Malik have indicated the integration of wind and hydro sources employing self-excited induction generators (SEIGs) [20]. Methods of analysis of such parallel connected SEIGs are also available in the literature [20-23]. Later, Goel et al [24] proposed a wind-hydro system employing squirrel-cage induction machines (SCIMs), which are operated as generators with battery 
storage. This system has a capability of bidirectional active and reactive power flow and also a controlled load voltage magnitude and frequency. The entire system was modelled and simulated using MATLAB to demonstrate the working of the system, which includes maximum power tracking, voltage and frequency control, harmonic elimination and load balancing. These systems have employed a squirrelcage machine excited with capacitors or reactive power supported through machine side converter for the extraction of wind energy. Such SEIGs with wind turbine will have restricted operating speed range and also the ratings of the power electronic controllers will be more against the doubly fed induction generators (DFIGs) [3, 7, 25]. Hence, in this paper, a DFIG-based stand-alone system has been proposed with PHSP and battery for better utilization of wind energy.

In the proposed system, DFIG has been employed for the extraction of wind power, whereas SCIM has been employed for PHSP. The excitation of the rotor of the wind-driven DFIG is established using a single inverter, which is a sinusoidal pulse width modulation (SPWM) inverter supplied through a set of batteries. SCIM in PHSP acts as a motor or generator depending on excess/deficit power from the wind. Detailed steady-state analysis of the proposed DFIG-SCIM-battery system operated with wind and PSHP has been developed and typical performance characteristics are presented in the paper. A prototype system has been developed in the laboratory for demonstrating the successful working of the proposed system. Experiments have also been conducted with various operating conditions and results are furnished in the paper.

\section{Description of the system}

Figure 1 shows a block diagram of the proposed standalone WEECS with hybrid storage devices. This system consists of (i) wind-driven DFIG with an SPWM inverterbattery bank connected at the rotor terminals, (ii) PHSP, i.e., SCIM coupled with reversible pump turbine (RPT) and (iii) isolated ac loads. The stator terminals of both machines (DFIG and SCIM) and isolated ac loads are connected together, which forms the Point of Common Coupling (PCC). At PCC, the voltage magnitude and frequency are maintained constant for any operating conditions. This is achieved by feeding appropriate voltage magnitude and frequency at the rotor terminals of the wind-driven DFIG for a given mechanical power input (which is proportional to the available wind energy) and effective load at the PCC. For this purpose, a two-loop controller, one for regulating the stator voltage magnitude and the other for frequency, has been implemented with this system [25-27] and operation of this closed-loop controller is given below.

\subsection{Stator voltage control strategy of DFIG}

A Constant Voltage and Frequency Controller (CVFC) for maintaining the voltage magnitude and frequency at the PCC has been developed using Digital Signal Processor (DSP) TMS320LF2407A. The CVFC adjusts the output voltage and frequency of SPWM inverter connected at the rotor terminals of DFIG for any operating conditions [25]. This CVFC consists of voltage and frequency control loops as shown in figure 2. In the frequency control loop, the actual and reference frequencies of voltage at the PCC are processed and error signal is generated. Then, this error signal is given to a PI controller to produce unit sine waves of slip frequency (=MF of SPWM inverter) with respect to rotational speed of DFIG. Similarly, in the voltage control loop, the actual and reference voltages at the PCC are processed and an error signal is generated. Then, this error signal is given to the PI controller, which gives the required MI for operating the SPWM inverter. Then, a reference signal is generated by multiplying the output of these two loops. This reference signal is compared with a triangular carrier signal of $5 \mathrm{kHz}$ frequency. The output of this stage is the required SPWM pulse for gating the IGBTs of SPWM inverter for maintaining the set value of voltage magnitude and frequency at the PCC.

\subsection{Battery charging/discharging mechanism}

It is known that the slip power is injected into the terminals of the doubly fed induction machine for operating it as a generator at sub-synchronous speed [25]. However, at super-synchronous speed, the slip power is extracted from the rotor terminals for generator operation. This operational aspect of the DFIG has been used for charging/discharging the batteries through the SPWM inverter connected at the rotor terminals. Hence, the charging or discharging of the battery is achieved by operating the DFIG at super-synchronous or sub-synchronous rotor speeds. At any operating point, the voltage level of the batteries is maintained within the minimum and maximum permissible limits. Further, the BIS supplies the reactive power requirement of the entire system.

In the proposed system, the battery will be charged when the wind power is more than the load power plus losses. When the battery is fully charged, the DFIG will be operated just above the synchronous speed for keeping it in trickle charging condition. If the wind power is still more, then the flexible/dump loads are added in the system for power balance. The battery will support for supplying isolated loads when the wind power is less. However, the duration of the support depends on the energy available in the battery. Further, if the voltage level of the battery goes below the minimum value, a portion of the loads is removed, so that the DFIG operates just above the 


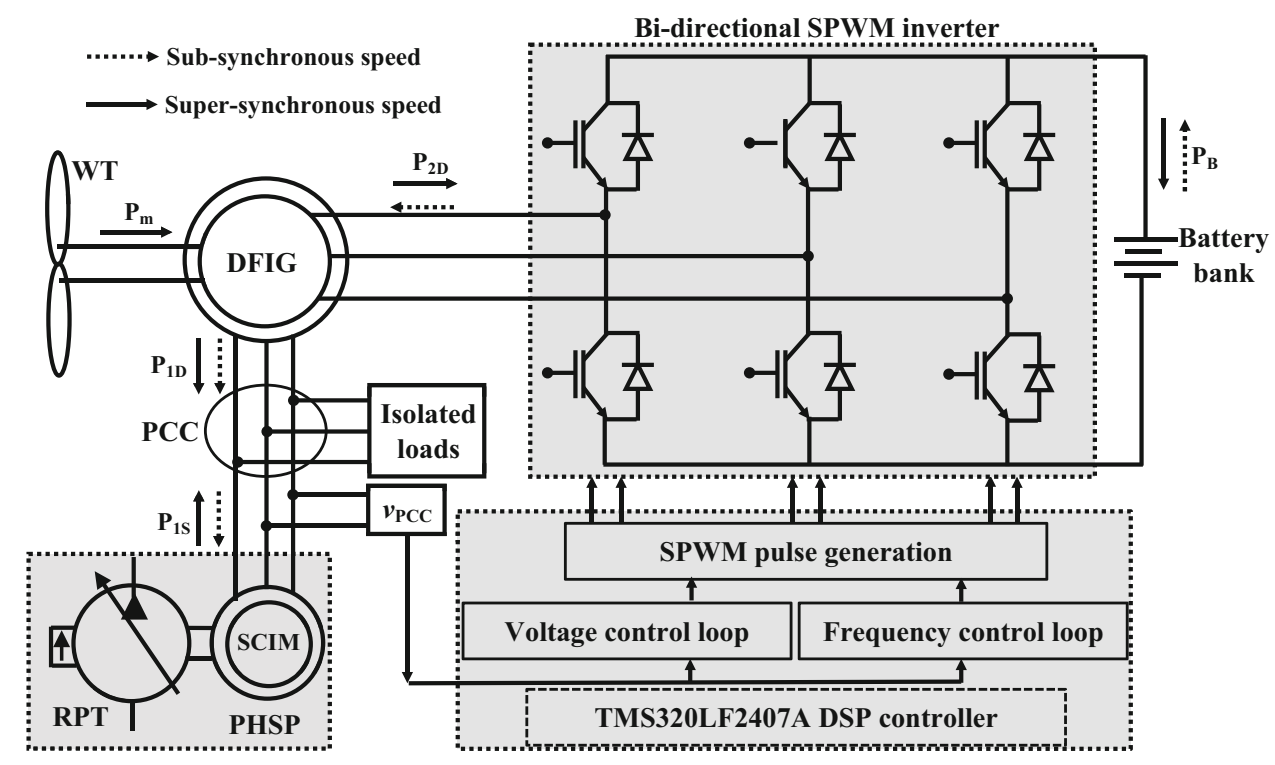

Figure 1. Block diagram of the proposed stand-alone DFIG with battery and pumped hydro storage system.

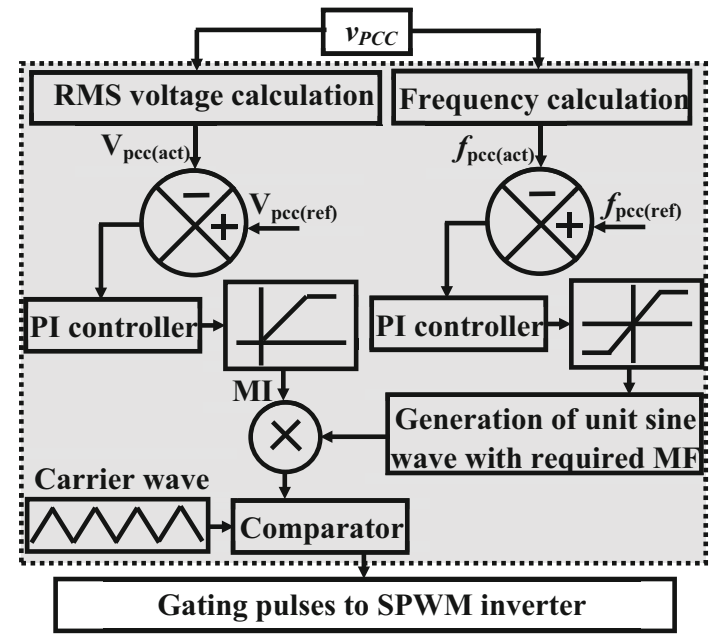

Figure 2. Schematic diagram of stator voltage and frequency control strategy of DFIG.

synchronous speed for keeping the batteries in minimum permissible voltage.

\subsection{Operation of PHSP}

As described in the previous section, PCC forms the virtual grid for operating the SCIM driven by RPT. As the voltage and frequency are constant, the SCIM operates as a motor for positive slip and generator for negative slip. The RPT can work either as pump or turbine, so that the excess or deficit wind power can be met by PHSP by operating SCIM as motor or generator, respectively. That is, during motoring operation, RPT operates as a pump; however, RPT operates as a turbine for generator operation of SCIM. It is to be noted that the reactive power requirement of SCIM for both motor and generator operations has been supplied from the stator terminals of wind-driven DFIG.

\subsection{Operating modes of the proposed system}

Depending upon the availability of the wind power and storage levels of battery and PHSP, the proposed system will have various modes of operation for supplying the isolated loads. These possible modes of operation are explained in figure 3 as a flowchart. This flowchart shows that the difference between the wind and load power is either stored in or extracted from the hybrid storage devices, namely, PHSP and battery, so that continuous and reliable power supply is ensured for isolated loads. Flexible loads such as space heating and water pumping are assumed to be present in the proposed system for managing the extreme operating conditions, namely, no or low wind power and rich wind with light load conditions. Further, for describing the modes, the minimum and maximum battery voltage levels and minimum and maximum water levels in the Upper Reservoir (UR) of PHSP have been considered.

\section{Steady-state analysis of the proposed system}

In the proposed topology, the isolated loads and stator terminals of DFIG and SCIM are connected at the PCC. The steady-state equivalent circuit consists of DFIG, SCIM and isolated loads connected in parallel at the PCC as shown in figure 4 for analysing the proposed system. All the machine parameters given in this equivalent circuit are 


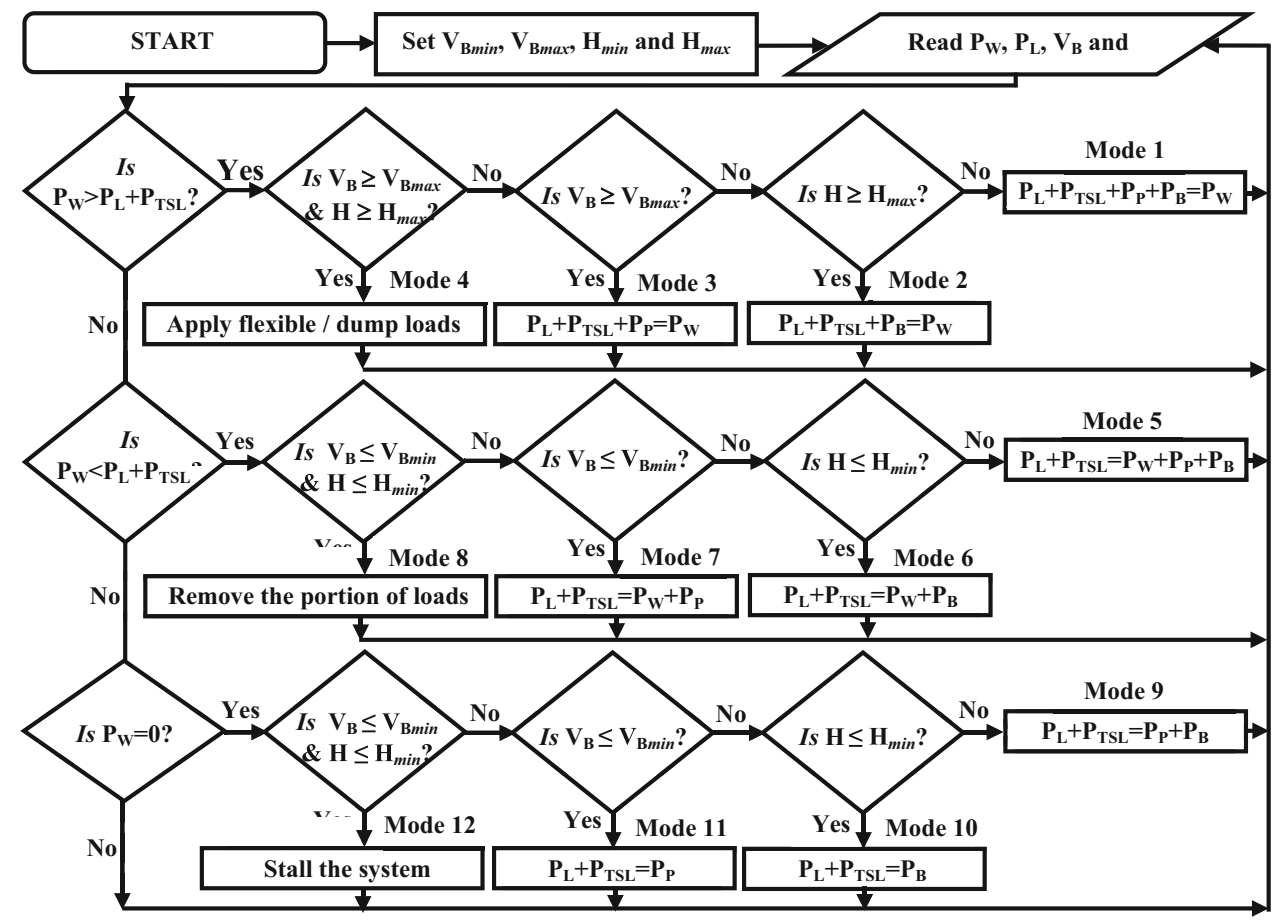

Figure 3. Flowchart for the operation of the proposed stand-alone DFIG with battery and pumped hydro storage system. $P_{\mathrm{W}}$ indicates the wind power input to DFIG (i.e., $P_{\mathrm{W}}=P_{\mathrm{mD}}$ ), $P_{\mathrm{B}}$ indicates battery power, $P_{\mathrm{TSL}}$ indicates total system loss, $P_{\mathrm{P}}$ indicates power drawn/ power generated from PHSP (i.e., $P_{\mathrm{P}}=P_{1 \mathrm{~S}}$ ) $H, H_{\mathrm{min}}$ and $H_{\mathrm{max}}$ indicate actual, minimum and maximum waterhead of PHSP, respectively, and $V_{\mathrm{B}}, V_{\mathrm{Bmin}}$ and $V_{\mathrm{Bmax}}$ indicate actual, minimum and maximum voltage of battery bank, respectively.

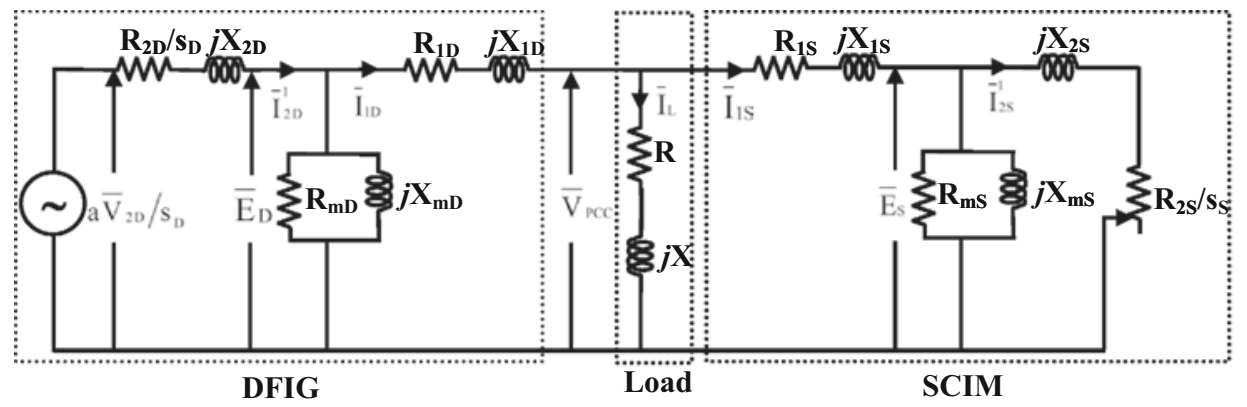

Figure 4. Steady-state equivalent circuit of the proposed system.

assumed to be constant. The voltage at the PCC is maintained constant at $415 \mathrm{~V}, 50 \mathrm{~Hz}$ by a closed-loop controller described in section 2.1. Hence, the performance quantities have been derived by taking this voltage $V_{\mathrm{PCC}}$ as the reference phasor.

\subsection{Expression for the performance quantities}

In figure 4 , operating slips of the DFIG and SCIM are $s_{\mathrm{D}}=$ $N_{\mathrm{SD}}-N_{\mathrm{RD}} / N_{\mathrm{SD}}$ and $s_{S}=N_{S S}-N_{R S} / N_{S S}$, respectively. In the proposed system, SCIM needs to operate either as a motor or generator for ensuring continuous power to the isolated loads. Hence, the positive value of $s_{\mathrm{s}}$ indicates the motoring operation of SCIM and negative value is for generator operation. However, the DFIG has been operated as a generator for both positive and negative value of slips (i.e., both at sub-synchronous and super-synchronous rotor speeds).

For the circuit shown in figure 4, the load current and input current of SCIM, respectively, are 


$$
\begin{gathered}
\bar{I}_{L}=\frac{\bar{V}_{P C C}}{R+j \mathrm{X}} \\
\bar{I}_{1 \mathrm{~S}}=\frac{\bar{V}_{\mathrm{PCC}}}{Z_{\mathrm{ES}}\left(s_{\mathrm{S}}\right)}
\end{gathered}
$$

where $Z_{\mathrm{ES}}\left(\mathrm{s}_{\mathrm{S}}\right)$ is the equivalent impedance of SCIM for a given operating slip of $s_{\mathrm{S}}$.

Then, the stator current of DFIG is

$$
\bar{I}_{1 D}=\bar{I}_{L}+\bar{I}_{1 S}
$$

The air-gap voltage of DFIG can be calculated as

$$
\bar{E}_{D}=\bar{V}_{\mathrm{PCC}}+\bar{I}_{1 \mathrm{D}}\left(R_{1 \mathrm{D}}+j \mathrm{X}_{1 \mathrm{D}}\right) .
$$

The rotor current and voltage (referred to stator), respectively, are

$$
\begin{gathered}
\bar{I}_{2 \mathrm{D}}^{1}=\bar{I}_{1 \mathrm{D}}+\frac{\bar{E}_{D}}{R_{\mathrm{mD}}}+\frac{\bar{E}_{D}}{j \mathrm{X}_{\mathrm{mD}}} \\
\bar{V}_{2 \mathrm{D}}^{1}=\bar{E}_{D}+\bar{I}_{2 \mathrm{D}}^{1}\left(\left(R_{2 \mathrm{D}} / s_{\mathrm{D}}\right)+j \mathrm{X}_{2 \mathrm{D}}\right) .
\end{gathered}
$$

Then, the required rotor voltage to be supplied from BIS can be calculated using the machine turns ratio and operating slip of DFIG. This expression is

$$
\bar{V}_{2 \mathrm{D}}=\bar{V}_{2 \mathrm{D}}^{1}\left(s_{\mathrm{D}} / \mathrm{a}\right)
$$

Similarly, the rotor current can be estimated as

$$
\bar{I}_{2 \mathrm{D}}=\mathrm{a} \bar{I}_{2 \mathrm{D}}^{1}
$$

Then, the modulation index of the inverter is determined using the following expression:

$$
m=2 \sqrt{2} \frac{\overline{V_{2 \mathrm{D}}}}{V_{\mathrm{dc}}} .
$$

The frequency of the voltage to be injected at the rotor terminals of DFIG is

$$
f_{\mathrm{rD}}=f_{\mathrm{PCC}}-\left(P_{\mathrm{D}} N_{\mathrm{sD}} / 120\right) \text { and } f_{\mathrm{PCC}}=50 \mathrm{~Hz}
$$

where $P_{\mathrm{D}}$ is the number of poles.

The stator real and reactive powers of DFIG, respectively, are

$$
P_{1 \mathrm{D}}=3 \operatorname{Re}\left(\bar{V}_{\mathrm{PCC}} \bar{I}_{1 \mathrm{D}}^{*}\right) \text { and } Q_{1 \mathrm{D}}=3 \operatorname{Im}\left(\bar{V}_{\mathrm{PCC}} \bar{I}_{1 \mathrm{D}}^{*}\right) .
$$

The rotor real and reactive powers of DFIG, respectively, are

$$
P_{2 \mathrm{D}}=3 \operatorname{Re}\left(\bar{V}_{2 \mathrm{D}} \bar{I}_{2 \mathrm{D}}^{*}\right) \quad \text { and } \quad Q_{2 \mathrm{D}}=3 \operatorname{Im}\left(\bar{V}_{2 \mathrm{D}} \bar{I}_{2 \mathrm{D}}^{*}\right) .
$$

here positive value of $P_{2 \mathrm{D}}$ indicates that the real power is injected into the rotor terminals for operating DFIG in subsynchronous rotor speeds and negative value indicates that the real power is extracted from rotor terminals at supersynchronous speed.
The mechanical power input to the DFIG is

$$
P_{\mathrm{mS}}=3\left(I_{2 \mathrm{D}}^{1}\right)^{2} R_{2 \mathrm{D}}\left(\frac{1-s_{\mathrm{D}}}{s_{\mathrm{D}}}\right)-P_{2 \mathrm{D}}\left(\frac{1-s_{\mathrm{D}}}{s_{\mathrm{D}}}\right) .
$$

The real power drawn/supplied at PCC for motoring/generator operation of SCIM can be calculated using

$$
P_{1 \mathrm{~S}}=3 \operatorname{Re}\left(\bar{V}_{\mathrm{PCC}} \bar{I}_{1 \mathrm{~S}}^{*}\right)
$$

The reactive power drawn by the SCIM for both motoring and generator operation is given by

$$
Q_{1 \mathrm{~S}}=3 \operatorname{Im}\left(\bar{V}_{\mathrm{PCC}} \bar{I}_{1 \mathrm{~S}}^{*}\right) \text {. }
$$

The air-gap voltage of a SCIM can be found using

$$
\begin{gathered}
\bar{E}_{\mathrm{S}}=\bar{V}_{\mathrm{PCC}}-\bar{I}_{1 \mathrm{~S}}\left(R_{1 \mathrm{~S}}+j \mathrm{X}_{1 \mathrm{~S}}\right) \\
\bar{I}_{2 \mathrm{~S}}=\bar{E}_{\mathrm{S}} /\left(\left(R_{2 \mathrm{~S}} / s_{\mathrm{S}}\right)+j \mathrm{X}_{2 \mathrm{~S}}\right) .
\end{gathered}
$$

Further, the total loss of SCIM and DFIG can be calculated by adding stator and rotor copper losses, core loss and constant mechanical power loss. The SPWM inverter loss has been calculated employing the method described in Graovac and Purchel [28] and Semikron [29].

\subsection{Performance characteristics}

To study the performance of the proposed system in various operating conditions, a 3-phase, 4-pole, $415 \mathrm{~V}, 50 \mathrm{~Hz}, 5$ $\mathrm{kVA}$, delta-connected slip-ring induction machine with 3-phase star-connected rotor of $200 \mathrm{~V}, 19 \mathrm{~A}$ and turns ratio of 3.6 has been considered for DFIG and a 3-phase, 4-pole, $415 \mathrm{~V}, 50 \mathrm{~Hz}, 3.5 \mathrm{kVA}$, star-connected squirrel-cage machine has been considered for SCIM. The measured parameters of the DFIG are $R_{1}=5.3 \Omega, R_{2}=2.4 \Omega$, $X_{1}=X_{2}=14.9 \Omega, R_{\mathrm{m}}=4871.1 \Omega$ and $X_{\mathrm{m}}=208.5 \Omega$. Similarly, SCIM parameters are $R_{1}=3.7 \Omega, R_{2}=2.7 \Omega$, $X_{1}=X_{2}=3.4 \Omega, R_{\mathrm{m}}=852 \Omega$ and $X_{\mathrm{m}}=132 \Omega$.

Figure 5 shows the predetermined performance characteristics of the proposed system for supplying constant real power to the isolated loads with unity power factor (UPF) and $0.95 \mathrm{PF}$ lagging. For plotting these characteristics, the mechanical power of SCIM $\left(P_{\mathrm{mS}}\right)$ has been taken as an independent variable. Positive value of $P_{\mathrm{mS}}$ indicates SCIM operating as motor for pumping the water to the UR, whereas negative value indicates generator operation. From this figure, it can be observed that DFIG supplies the real power with $P_{1 \mathrm{D}}=P_{\mathrm{L}}+P_{1 \mathrm{~S}}$ and reactive power $Q_{1 \mathrm{D}}=-$ $Q_{\mathrm{L}}+Q_{1 \mathrm{~S}}$. As an example, for a $2 \mathrm{~kW}$, UPF load $P_{1 \mathrm{D}}=3.3 \mathrm{~kW}, P_{1 \mathrm{~s}}=1.3 \mathrm{~kW}$ for $P \mathrm{~ms}=1 \mathrm{~kW}$. In this condition $Q_{1 \mathrm{D}}=Q_{1 \mathrm{~S}}=1.4 \mathrm{kVAR}$, since $Q_{\mathrm{L}}=0$ for UPF load. For supplying this real power $P_{1 \mathrm{D}}$, DFIG has to operate in sub-synchronous or super-synchronous rotor speed for meeting out the deficit/excess wind power from the battery. For the same load setting described above, 


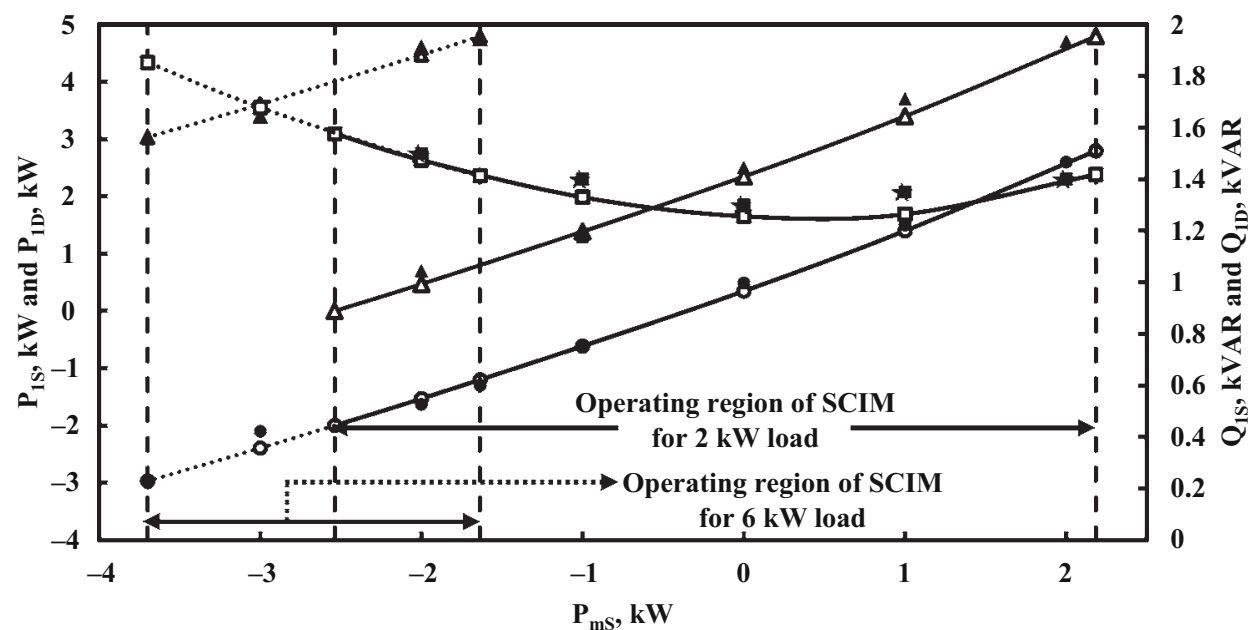

(a) UPF load

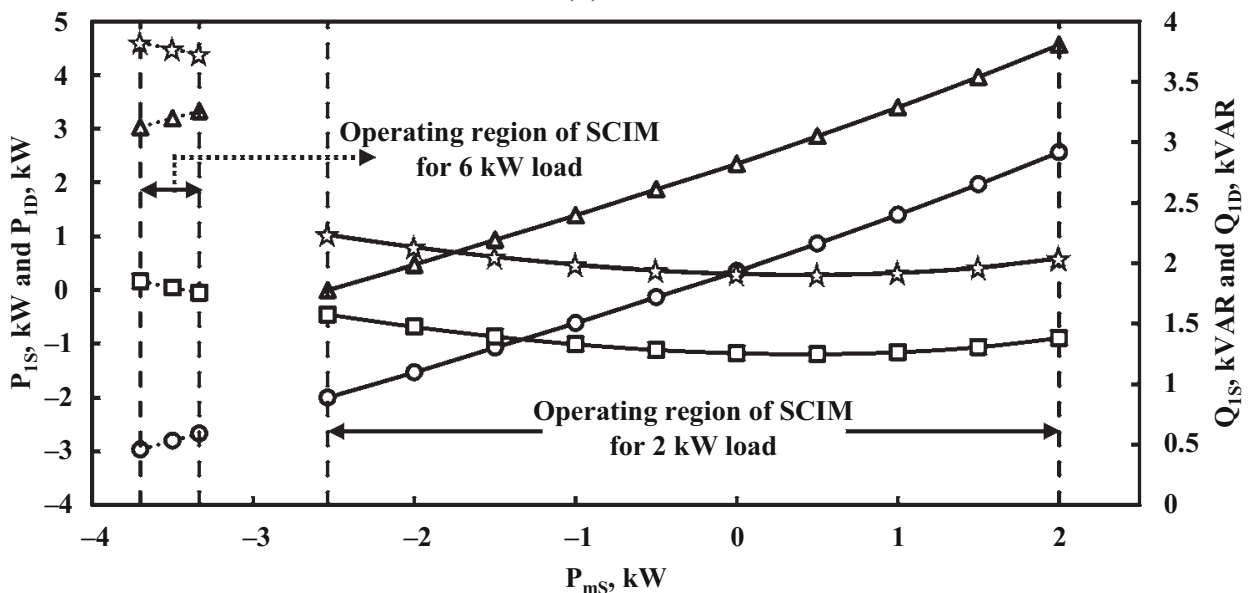

(b) 0.95 lagging $\mathrm{PF}$

Figure 5. Steady-state performance of the system $\left(V_{\mathrm{PCC}}=415 \mathrm{~V}, f_{\mathrm{PCC}}=50 \mathrm{~Hz}\right.$ and $\left.V_{\mathrm{dc}}=168 \mathrm{~V}\right) .-2 \mathrm{~kW}$ load; $\cdots . .6 \mathrm{~kW}$; calculated: $\boldsymbol{\circ} P_{1 \mathrm{~S}}, \boldsymbol{\square} Q_{1 \mathrm{~S}}, \boldsymbol{\Delta} P_{1 \mathrm{D}}, \star Q_{1 \mathrm{D}}$ and experimental: $\bullet P_{1 \mathrm{~S}}, \boldsymbol{\square} Q_{1 \mathrm{~S}}, \boldsymbol{\Delta} P_{1 \mathrm{D}}, \star Q_{1 \mathrm{D}}$.

$P_{\mathrm{mD}}=2.9 \mathrm{~kW}$ and $P_{2 \mathrm{D}}=0.8 \mathrm{~kW}$ for $N_{\mathrm{RD}}=1200 \mathrm{rpm}$. As DFIG is operated at sub-synchronous speed, the battery should supply this value of $P_{2 \mathrm{D}}$ at rotor terminals.

For drawing these characteristics of figure 5, it is assumed that the SCIM is connected at the PCC even for $P_{\mathrm{mS}}=0$. If SCIM is disconnected from the PCC for this operating point, then there will be a slight change in the real and reactive powers given in figure 5 at $P_{\mathrm{mS}}=0$. That is, for the same $2 \mathrm{~kW}$, UPF load, with SCIM connected, $P_{1 \mathrm{D}}=2.3 \mathrm{~kW}, Q_{1 \mathrm{D}}=1.2 \mathrm{kVAR}, P_{1 \mathrm{~S}}=0.3 \mathrm{~kW}$ (which is equal to the losses in SCIM) and $Q_{1 \mathrm{~S}}=1.2 \mathrm{kVAR}$. With SCIM disconnected, $Q_{1 \mathrm{D}}, P_{1 \mathrm{~S}}$ and $Q_{1 \mathrm{~S}}$ are zero except $P_{1 \mathrm{D}}$ $\left(=P_{\mathrm{L}}\right)$.

It is interesting to note from figure 5 that the boundary for operating range of SCIM depends on the value of isolated load as well as DFIG kVA rating. For explaining this concept, predetermination has also been carried out for typical values of loads and PFs and the results are given in table 1. From this table and figure 5, it can be observed that the Right Extreme Boundary Point (REBP) of SCIM has been fixed based on the SCIM or DFIG rating for the given load. For no-load or light-load conditions, the SCIM can operate as a motor with its rated capacity of $3.5 \mathrm{kVA}$.

For the increased value of loads, this value will decrease, since DFIG will reach its rated capacity as that of SCIM rating. For higher value of loads, SCIM will operate only as a generator for supplying the isolated loads along with the DFIG. Similarly, Left Extreme Boundary Point (LEBP) of SCIM has been fixed based on the load or SCIM rating. At this point, wind power is zero and the entire load power is met by operating the SCIM as a generator.

The power delivered at the stator of DFIG, $P_{1 \mathrm{D}}$ $\left(=P_{\mathrm{L}}+P_{1 \mathrm{~S}}\right)$ shown in figure 5 and table 1 , is independent of wind power, battery power and rotor speed. Hence, to 
Wind-driven stand-alone DFIG with battery and pumped hydro

Table 1. Operating boundary for SCIM; $P_{\mathrm{L}}=2 \mathrm{~kW}$, UPF load; $V_{\mathrm{PCC}}=415 \mathrm{~V}, f_{\mathrm{PCC}}=50 \mathrm{~Hz}$ and $V_{\mathrm{dc}}=168 \mathrm{~V}$.

\begin{tabular}{|c|c|c|c|c|c|c|c|c|c|c|}
\hline \multirow[b]{2}{*}{ S1. no. } & \multicolumn{2}{|c|}{ Load } & \multicolumn{3}{|c|}{ REBP operation of SCIM } & \multirow[b]{2}{*}{ Condition } & \multicolumn{3}{|c|}{ LEBP operation of SCIM } & \multirow[b]{2}{*}{ Condition } \\
\hline & $\mathrm{kW}$ & $\mathrm{PF}$ & $P_{1 \mathrm{~S}}, \mathrm{~kW}$ & $Q_{1 \mathrm{~S}}, \mathrm{kVAR}$ & $P_{\mathrm{mS}}, \mathrm{kW}$ & & $P_{1 \mathrm{~S}}, \mathrm{~kW}$ & $Q_{1 \mathrm{~S}}, \mathrm{kVAR}$ & $P_{\mathrm{mS}}, \mathrm{kW}$ & \\
\hline 1 & \multicolumn{2}{|c|}{ No load } & 3.16 & 1.48 & 2.47 & Con. 1 & 0 & 0 & 0 & $P_{\mathrm{L}}=P_{1 \mathrm{~s}}$ \\
\hline 2 & 2 & 1 & 2.79 & 1.41 & 2.18 & Con. 2 & -2 & 1.57 & -2.53 & $P_{\mathrm{L}}=P_{1 \mathrm{~s}}$ \\
\hline 3 & 2 & 0.95 & 2.56 & 1.38 & 2.00 & Con. 2 & -2 & 1.57 & -2.53 & $P_{\mathrm{L}}=P_{1 \mathrm{~s}}$ \\
\hline 4 & 2 & 0.8 & 2.12 & 1.32 & 1.67 & Con. 2 & -2 & 1.57 & -2.53 & $P_{\mathrm{L}}=P_{1 \mathrm{~s}}$ \\
\hline 5 & 4 & 1 & 0.84 & 1.24 & 0.48 & Con. 2 & -2.96 & 1.85 & -3.70 & Con. 1 \\
\hline 6 & 4.49 & 1 & 0.34 & 1.25 & 0 & Con. 2 & -2.96 & 1.85 & -3.70 & Con. 1 \\
\hline 7 & 6 & 1 & -1.20 & 1.41 & -1.68 & Con. 2 & -2.96 & 1.85 & -3.70 & Con. 1 \\
\hline 8 & 6 & 0.95 & -2.67 & 1.75 & -3.33 & Con. 2 & -2.96 & 1.85 & -3.70 & Con. 1 \\
\hline
\end{tabular}

Positive value of $P_{\mathrm{mS}}$ indicates that SCIM is operated as motor and negative value indicates generator operation of SCIM, Con. 1 indicates that SCIM reached rated $\mathrm{kVA}$ and Con. 2 indicates that DFIG reached rated kVA.

show the operational aspects of the proposed system with various modes mentioned in the flowchart of figure 3, predetermination of the performance of the system has been carried out for different operating slips of DFIG and $P_{\mathrm{ms}}$. For the sake of brevity, these predetermined characteristics are given in figure 6 for one value of load ( $2 \mathrm{~kW}$, UPF).

Figure 6a shows the variation stator current $I_{1 \mathrm{D}}$ against $P_{\mathrm{mS}}$ and $s_{\mathrm{D}}$. It can be observed from this figure that the stator current is constant for all values of $s_{\mathrm{D}}$ for a given $P_{\mathrm{mS}}$, since a constant value of $P_{1 \mathrm{D}}$ needs to be supplied by DFIG for satisfying $\left(P_{\mathrm{L}}+P_{1 \mathrm{~S}}\right)$. The stator current $I_{1 \mathrm{D}}$ will increase for the increased value of $P_{1 \mathrm{D}}$, which depends on $P_{\mathrm{mS}}$ for the given isolated load. It is to be noted that the $I_{1 \mathrm{D}}$ will increase with decreased value of the load PF for supplying the same load $P_{\mathrm{L}}$ with the same $P_{1 \mathrm{D}}$ and $P_{\mathrm{ms}}$. Similar observations are noted for the variation of rotor current $I_{2 \mathrm{D}}$ against $P_{\mathrm{ms}}$ and $s_{\mathrm{D}}$ and results are given in figure $6 \mathrm{~b}$. Figure $6 \mathrm{c}$ shows the variation of rotor voltage $V_{2 \mathrm{D}}$ against $P_{\mathrm{mS}}$ and $s_{\mathrm{D}}$. From this figure, it can be observed that the rotor voltage magnitude increases with $s_{\mathrm{D}}$, both in sub-synchronous and super-synchronous rotor speeds of DFIG for the given $P_{\mathrm{ms}}$. Similarly, rotor reactive power also varies with $s_{\mathrm{D}}$ and the results are given in figure $6 \mathrm{~d}$. It should be noted that the reactive power injected into the rotor terminal will increase for the decreased value of load $\mathrm{PF}$ for the same $s_{\mathrm{D}}$. Variation of rotor real power $P_{2 \mathrm{D}}$ and battery power $P_{\mathrm{B}}$ against $P_{\mathrm{ms}}$ and $s_{\mathrm{D}}$ are given in figure $6 \mathrm{e}$ and $6 \mathrm{f}$, respectively. Figure $6 \mathrm{f}$ shows that the battery supports the power balance of the proposed system at PCC by charging or discharging. It is to be noted that the proposed system can support the isolated loads even with no-wind condition, based on the availability of energy in battery and PHSP.

For explaining the various modes of operation of the proposed system, typical values of the power at various points along with $s_{\mathrm{D}}$ are given in table 2 . Although battery voltage reached the maximum specified value at mode 3 , the DFIG is operated slightly above synchronous speed to operate the battery in trickle charging mode. Hence, in practical conditions, power balance equation becomes $P_{\mathrm{L}}+P_{\mathrm{TSL}}+P_{1 \mathrm{~S}}+P_{\mathrm{B}}=P_{\mathrm{mD}}$ under this mode of operation. Similarly, in mode 6 , though the battery voltage reaches the minimum specified voltage, the BIS cannot supply the reactive power of the system with this minimum voltage. Hence, in this mode also, DFIG is made to operate slightly above synchronous speed for maintaining the battery voltage above the minimum specified value. Hence, power balance under this condition becomes $P_{\mathrm{L}}+P_{\mathrm{TSL}}+P_{\mathrm{B}}=P_{\mathrm{mD}}+P_{1 \mathrm{~S}}$.

\section{Experimental investigations}

To confirm the successful working of the proposed system shown in figure 1, a prototype system has been fabricated with the same electrical machines mentioned in section 3.2. A three-phase SPWM inverter has been used for feeding variable voltage and frequency at the rotor terminals of DFIG. This SPWM inverter is built using IGBTs (SKM300GB125D) along with suitable gate driver circuits. LEM make voltage transducer (LV-25) has been used to sense voltage magnitude and frequency at the PCC. The output of this voltage transducer is appropriately scaled down by a signal conditioning circuit and then fed to the analog-digital converter available in TMS320LF2407A Digital Signal Processor (DSP). The control strategy given in section 2.1 has been programmed using this DSP for maintaining the set value of voltage and frequency at PCC. As given in figure 2, this involves starting from the calculation of rms value of voltage and frequency, and obtaining errors to the generation of pulses for gating IGBTs in SPWM inverter shown in figure 1. The successful working of this CVFC control strategy for maintaining the constant voltage magnitude and frequency at the stator terminals of standalone wind-driven DFIG with BIS has already been 


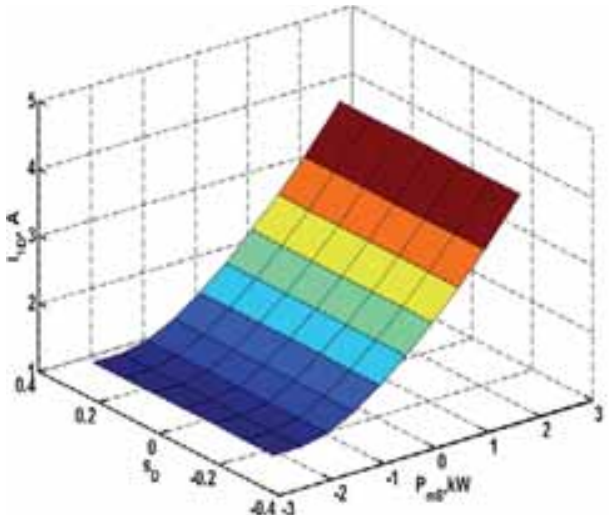

(a) Variation of $I_{1 \mathrm{D}}$ against $s_{\mathrm{D}}$ and $P_{\mathrm{as}}$

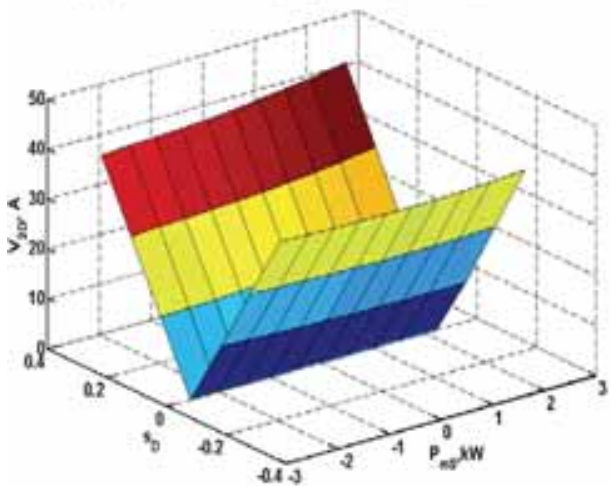

(c) Variation of $V_{2 D}$ against $s_{D}$ and $P_{n s}$

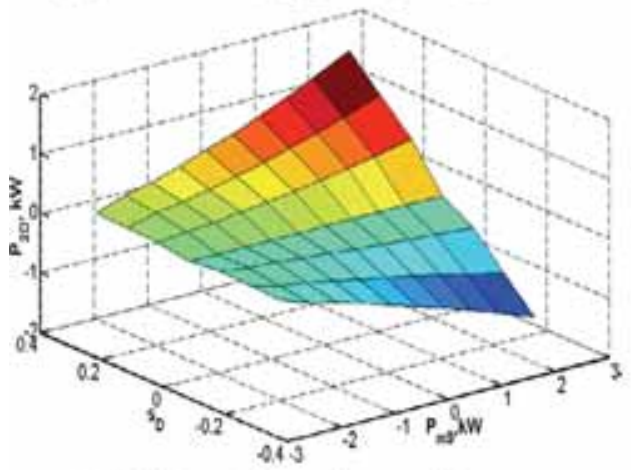

(e) Variation of $P_{\mathrm{m}}$ against $s_{\mathrm{D}}$ and $P_{\mathrm{ns}}$

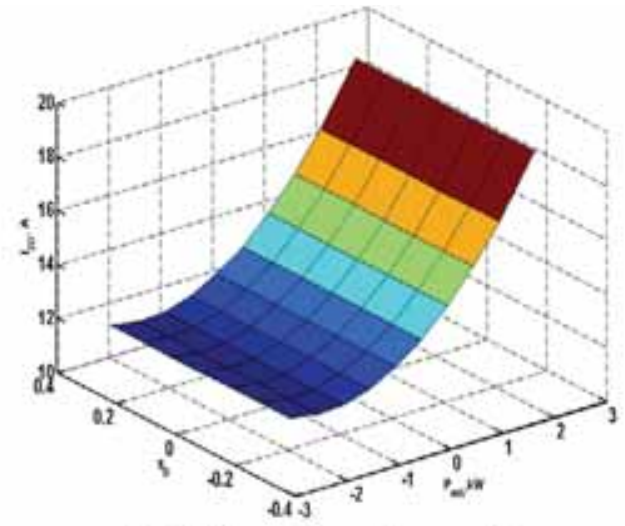

(b) Vaxiation of $I_{2 \mathrm{D}}$ against $s_{\mathrm{D}}$ and $P_{\mathrm{m}}$

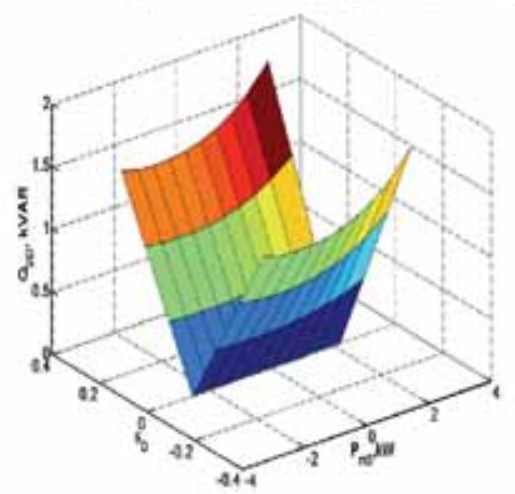

(d) Variation of $Q_{2 D}$ against $s_{\mathrm{D}}$ and $P_{\mathrm{mas}}$

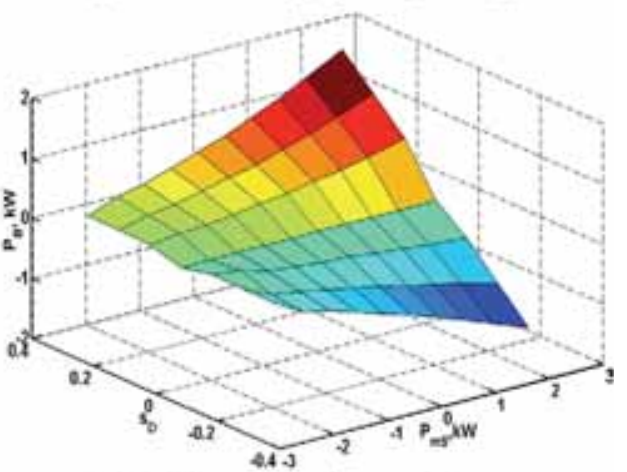

(f) Variation of $P_{3}$ against $S_{\mathrm{D}}$ and $P_{\mathrm{ms}}$

Figure 6. Steady-state performance of the proposed system for $2 \mathrm{~kW}$, UPF load; $V_{\mathrm{PCC}}=415 \mathrm{~V}, f_{\mathrm{PCC}}=50 \mathrm{~Hz}$ and $V_{\mathrm{dc}}=168 \mathrm{~V}$. (a) Variation of $I_{1 \mathrm{D}}$ against $s_{\mathrm{D}}$ and $P_{\mathrm{ms}}$. (b) Variation of $I_{2 \mathrm{D}}$ against $s_{\mathrm{D}}$ and $P_{\mathrm{ms}}$. (c) Variation of $V_{2 \mathrm{D}}$ against $s_{\mathrm{D}}$ and $P_{\mathrm{ms}}$. (d) Variation of $Q_{2 \mathrm{D}}$ against $s_{\mathrm{D}}$ and $P_{\mathrm{ms}}$. (e) Variation of $P_{2 \mathrm{D}}$ against $s_{\mathrm{D}}$ and $P_{\mathrm{ms}}$. (f) Variation of $P_{\mathrm{B}}$ against $s_{\mathrm{D}}$ and $P_{\mathrm{ms}}$.

verified experimentally in the laboratory for various operating conditions [25]. Further, it has been shown that the DFIG automatically operates in super-synchronous/sub-synchronous rotor speeds depending upon the availability of wind energy and size of the ac load with CVFC. Hence, in the present work, the same CVFC has been employed for maintaining a constant voltage magnitude and frequency at the PCC for any operating conditions. Now, it is of interest to show the working of the proposed stand-alone WEECS with PHSP and battery storage devices for various operating modes described in the flowchart of figure 3 .

To evaluate the performance of the proposed system, experiments have been conducted on the same DFIG and SCIM described in section 2. A separately excited DC motor was used as the prime mover to drive DFIG. Similarly, SCIM has been coupled with a separately excited DC machine for the emulation of PHSP. For emulating the pumping operation of PHSP, the DC machine has been operated as a generator, which acted as a load on the motoring operation of SCIM. On 
Table 2. Performance of the proposed system for various operating modes; $P_{\mathrm{L}}=2 \mathrm{~kW}$, UPF load; $V_{\mathrm{PCC}}=415 \mathrm{~V}$ and $f_{\mathrm{PCC}}=50 \mathrm{~Hz}$.

\begin{tabular}{|c|c|c|c|c|c|c|c|c|c|c|c|c|c|}
\hline \multirow[b]{2}{*}{ Operating mode } & \multirow[b]{2}{*}{$s_{\mathrm{D}}$} & \multicolumn{2}{|c|}{$P_{\mathrm{mD}}, \mathrm{kW}$} & \multicolumn{2}{|c|}{$P_{\mathrm{mS}}, \mathrm{kW}$} & \multicolumn{2}{|c|}{$P_{1 \mathrm{~S}}, \mathrm{~kW}$} & \multicolumn{2}{|c|}{$P_{\mathrm{B}}, \mathrm{kW}$} & \multicolumn{2}{|c|}{$P_{\mathrm{TSL}}, \mathrm{kW}$} & \multirow[b]{2}{*}{ Battery status } & \multirow[b]{2}{*}{ PHSP status } \\
\hline & & Cal & Exp & $\mathrm{Cal}$ & Exp & $\mathrm{Cal}$ & Exp & Cal & Exp & Cal & Exp & & \\
\hline Mode 1 & -0.3 & 6.62 & 6.83 & 2 & 2.1 & 2.56 & 2.63 & 1.36 & 1.41 & 0.70 & 0.8 & Charging & Pumping \\
\hline Mode 2 & -0.3 & 2.98 & 3.01 & 0 & 0 & 0 & 0 & 0.59 & 0.62 & 0.39 & 0.39 & Charging & - \\
\hline Mode 3 & -0.06 & 5.47 & 5.65 & 2 & 2.1 & 2.56 & 2.63 & 0.21 & 0.24 & 0.7 & 0.78 & Trickle charging & Pumping \\
\hline Mode 4 & \multicolumn{13}{|c|}{ In this mode, flexible/dump load of sufficient magnitude has been switched on for maintaining power balance } \\
\hline Mode 5 & 0.3 & 0.72 & 0.8 & 2 & 2.1 & 1.53 & 1.63 & 0.35 & 0.4 & 0.60 & 0.72 & Discharging & Generation \\
\hline Mode 6 & -0.3 & 1.17 & 1.32 & 2 & 2.1 & 1.53 & 1.64 & 0.19 & 0.22 & 0.51 & 0.62 & Trickle charging & Generation \\
\hline Mode 7 & 0.3 & 1.69 & 1.81 & 0 & 0 & 0 & 0 & 0.90 & 0.98 & 0.59 & 0.63 & Discharging & - \\
\hline Mode 8 & \multicolumn{13}{|c|}{ In this mode, the portion of flexible load can be removed to maintain power balance } \\
\hline Mode 9 & 1 & - & - & 2 & 2.05 & 1.53 & 1.59 & 0.69 & 0.8 & 0.22 & 0.3 & Discharging & Generation \\
\hline Mode 10 & 1 & - & - & 0 & - & 0 & - & 2.20 & 2.25 & 0.20 & 0.28 & Discharging & - \\
\hline Mode 11 & 1 & - & - & 2.53 & 2.65 & 2 & 2.1 & 0 & - & 0.53 & 0.61 & Slow discharge & Generation \\
\hline
\end{tabular}

(i) $P_{1 \mathrm{D}}=P_{\mathrm{L}}+P_{1 \mathrm{~S}}$, (ii) $P_{\mathrm{mD}}$ includes mechanical loss of DFIG and BIS loss and (iii) mechanical losses of $0.15 \mathrm{~kW}$ and $0.12 \mathrm{~kW}$ have been taken for DFIG and SCIM, respectively.

the other hand, DC machine operates as a motor, so that SCIM will operate as a generator, for emulating the turbine operation of PHSP. Experiment was conducted for two different UPF loads, namely, 2 and $6 \mathrm{~kW}$ at the PCC. Throughout the experiment, $415 \mathrm{~V}, 50 \mathrm{~Hz}$ has been maintained at the PCC by CVFC. The CVFC has been developed using a TMS320LF2407A DSP. The variations of $P_{1 \mathrm{~S}}, P_{1 \mathrm{D}}$, $Q_{1 \mathrm{~S}}, Q_{1 \mathrm{D}}, I_{1 \mathrm{D}}, I_{2 \mathrm{D}}, V_{2 \mathrm{D}}, Q_{2 \mathrm{D}}, P_{2 \mathrm{D}}$ and $P_{\mathrm{B}}$ with $P_{\mathrm{mS}}$ were observed and these experimental results have also been presented in figure 3 along with the corresponding predetermined values. A close agreement between the experimental and predetermined values confirms the practical working of the system and validates the proposed method of analysis. Experiments have also been conducted for supplying $2 \mathrm{~kW}$, UPF load with typical DFIG slip and $P_{\mathrm{ms}}$. The corresponding experimental results of $P_{1 \mathrm{D}}, P_{\mathrm{mS}}, P_{\mathrm{B}}$ and $P_{\mathrm{mD}}$ along with $s_{\mathrm{D}}$ and $P_{\mathrm{mS}}$ are also given in table 2. This table confirms the working of the proposed system in various modes of operation as described in the flowchart of figure 3 .

Experiments have also been conducted for validating the successful working of the proposed system for step change in the ac load $\left(P_{\mathrm{L}}\right)$ at PCC and rotor speeds of DFIG and SCIM. Firstly, the performance of the system has been tested for a constant speed operation of DFIG and SCIM for step change in $P_{\mathrm{L}}$. Figures 7-9 show the oscillographic waveforms of the voltage at PCC $\left(V_{\mathrm{PCC}}\right)$, stator current $\left(I_{1 \mathrm{D}}\right)$, rotor voltage $\left(V_{2 \mathrm{D}}\right)$ and rotor current $\left(I_{2 \mathrm{D}}\right)$ of DFIG and stator current $\left(I_{1 \mathrm{~S}}\right)$ of SCIM for a step change in $P_{\mathrm{L}}$. In figure 7, no-load to $1 \mathrm{~kW}$, UPF has been initiated at PCC by operating SCIM as a motor consuming $P_{1 \mathrm{~S}}=1.5 \mathrm{~kW}$ and $Q_{1 \mathrm{~S}}=1.27 \mathrm{kVAR}$ with $N_{\mathrm{RS}}=1465 \mathrm{rpm}$. It can be observed from this figure that (i) the DFIG supplies the power requirement of SCIM and $P_{\mathrm{L}}$, (ii) the stator current of SCIM is constant for any value of $P_{\mathrm{L}}$ and $N_{\mathrm{RD}}$, (iii) the DFIG stator and rotor currents increase for increased $P_{\mathrm{L}}$, (iv) for any $N_{\mathrm{RD}}$, rotor current of DFIG is constant for a given $P_{1 \mathrm{D}}$ and (v) rotor voltage and power of DFIG change with $N_{\mathrm{RD}}$ and $P_{1 \mathrm{D}}$.

A similar experiment has been conducted for higher values of step change in $P_{\mathrm{L}}$, i.e., $5 \mathrm{~kW}$, UPF to $6 \mathrm{~kW}$, UPF load and the results are given in figure 8 . For conducting this experiment, SCIM has been operated as a generator with $P_{1 \mathrm{~S}}=2.96 \mathrm{~kW}, \quad Q_{1 \mathrm{~S}}=1.85 \quad \mathrm{kVAR} \quad$ and $N_{\mathrm{RS}}=1576 \mathrm{rpm}$, so that the REBP of the system is well within the limits. Experiments have been conducted for simultaneous change of rotor speeds of DFIG and SCIM and results are given in figure 9 for a constant UPF load of $3 \mathrm{~kW}$. It is to be noted that the rotational speed of winddriven generators will not change instantaneously even for gust wind. The predicted and experimental results given in figures 5-9 and table 2 show the efficacy of the proposed WEECS for supplying isolated loads.

\section{Conclusions}

A system consisting of a wind-driven DFIG, BIS and PHSP suitable for the development of MW level stand-alone power generation has been proposed. In this system, SCIM has been coupled with RPT to form a PHSP. The SCIM may operate as a motor or generator based on the availability of power and load demand. Further, the isolated loads, stator terminals of DFIG and SCIM are connected at the PCC. Hence, a method has been developed starting from the formulation of the steady-state equivalent circuit for analysing such parallel operated DFIG and SCIM along with the BIS. The set values of voltage magnitude and frequency at the PCC have been maintained within the limits by using a TMS320LF2407A-DSP-based closed-loop controller. 

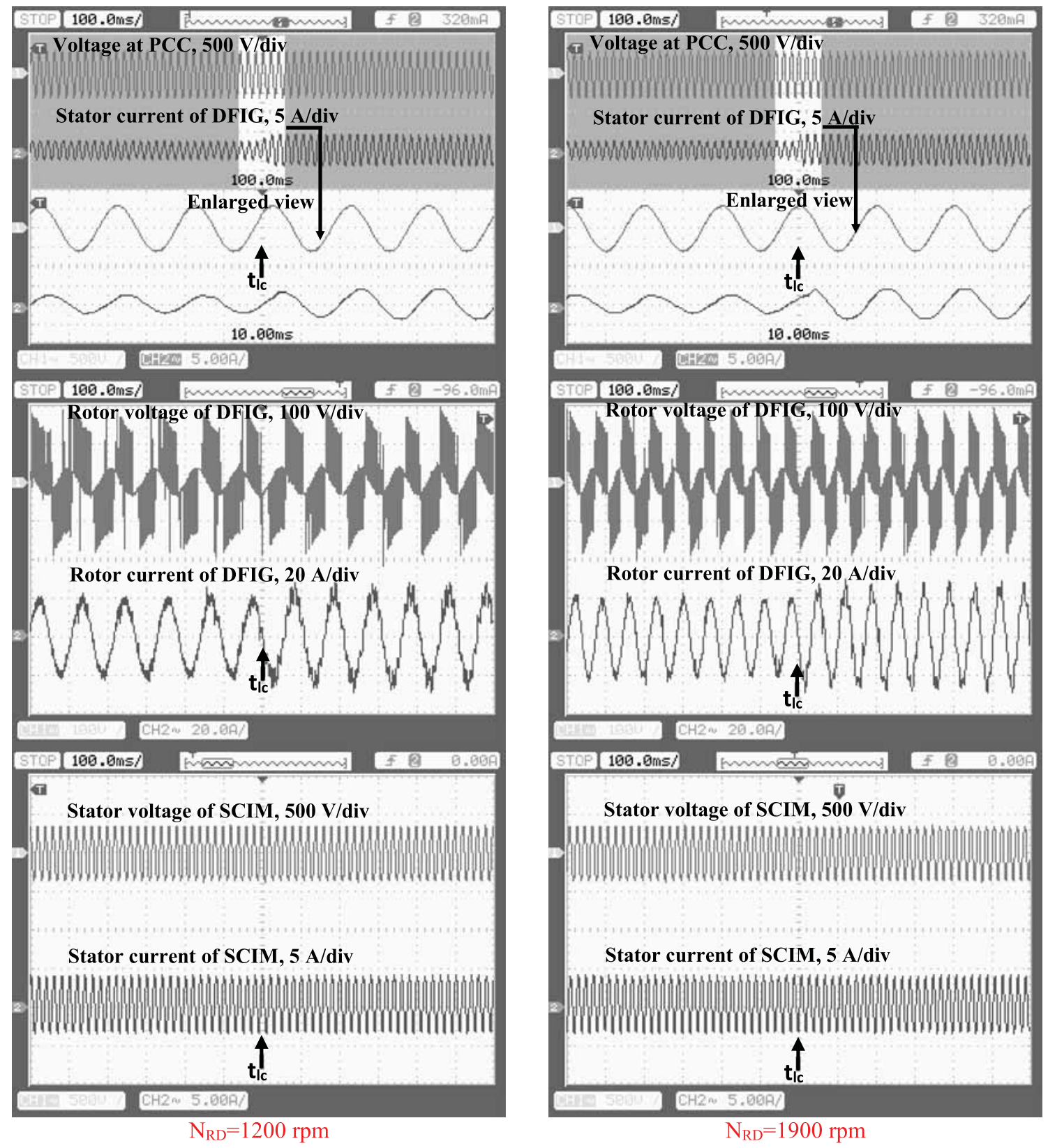

Figure 7. Dynamic response of the system for change in load from no-load to $1 \mathrm{~kW}$, UPF load; $P_{1 \mathrm{~s}}=1.5 \mathrm{~kW}$ (motoring) and $N_{\mathrm{RS}}=1465 \mathrm{rpm}, t_{\mathrm{lc}}$ : instant at which load change is initiated and time axis: $100 \mathrm{~ms} / \mathrm{div}$ except for enlarged view, for which it is $10 \mathrm{~ms} / \mathrm{div}$.

A more practical way of integrating two energy storage devices, namely, battery and PHSP with stand-alone WEECS, has been shown for effectively managing the available wind power and load requirement. Thus, the proposed system will operate in different modes for supplying the continuous power to the isolated loads. All such possible operating modes of the proposed system are clearly brought out in this paper. The occurrences of these modes are shown with predetermined performance characteristics of the proposed system. Further, the operating boundaries for the proposed system are also clearly brought out for supplying a given load at the PCC. All these predetermined characteristics are amply validated with the experimental results obtained on a prototype system developed in the laboratory.

\section{Acknowledgements}

Funding was provided by National Institute of Wind Energy Technology (NIWE) Under Ministry of New and Renewable Energy, Government of India. 


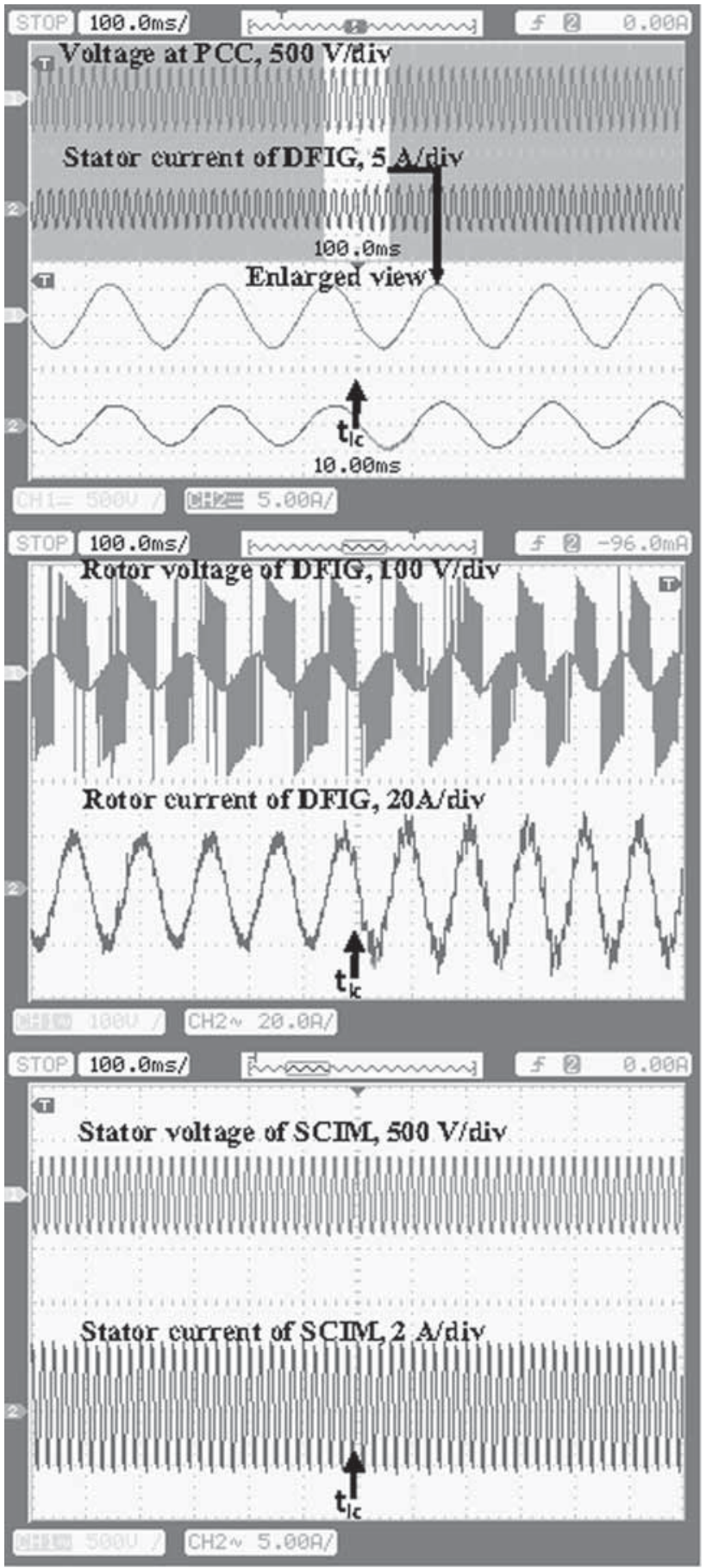

Figure 8. Dynamic response of the system for step change in load from $5 \mathrm{~kW}$, UPF to $6 \mathrm{~kW}$, UPF; $P_{1 \mathrm{~S}}=2.96 \mathrm{~kW}$ (generation) and $N_{\mathrm{RS}}=1576 \mathrm{rpm}, t_{\mathrm{lc}}$ : instant at which load change is initiated and time axis: $100 \mathrm{~ms} / \mathrm{div}$ except for enlarged view, for which it is $10 \mathrm{~ms} / \mathrm{div}$.

\section{Appendix}

A

$E_{\mathrm{D}}, E_{\mathrm{S}}$

Stator-to-rotor turns ratio of DFIG

Per phase air-gap voltage of DFIG and SCIM, V

$f_{\mathrm{PCC}}$

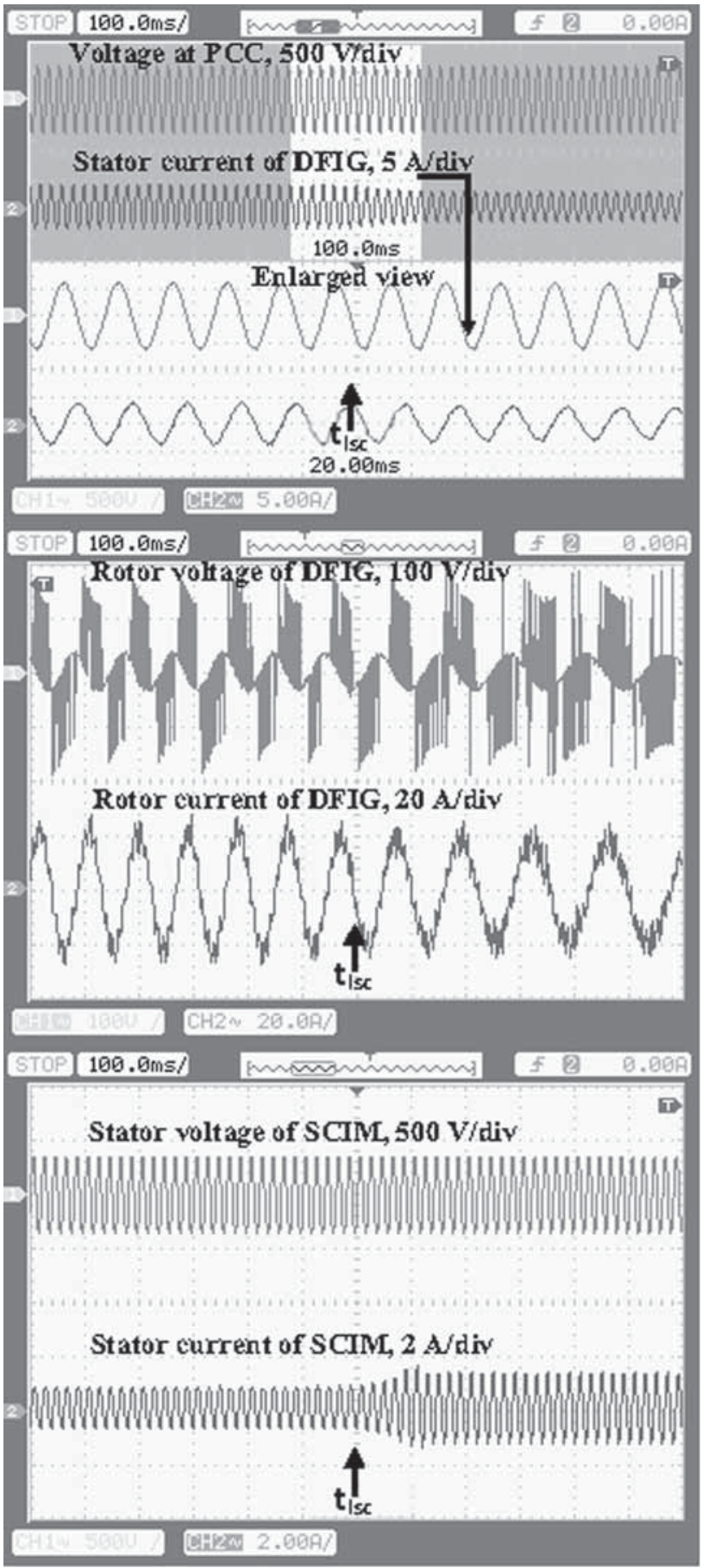

Figure 9. Dynamic response of the system with simultaneous change of speeds of DFIG and SCIM for a constant load of $3 \mathrm{~kW}$, UPF; $N_{\mathrm{RD}}=1200-1300 \mathrm{rpm}$ and $N_{\mathrm{RS}}=1490-1530 \mathrm{rpm}, t_{\mathrm{lsc}}$ : instant at which simultaneous speed change is initiated and time axis: $100 \mathrm{~ms} / \mathrm{div}$ except for enlarged view, for which it is $10 \mathrm{~ms} / \mathrm{div}$.

$I_{\mathrm{L}}, I_{1 \mathrm{D}}, I_{1 \mathrm{~S}} \quad$ Per phase load and stator current of DFIG and SCIM, respectively, A

$I_{2 \mathrm{D}}^{1}$ and $I_{2 \mathrm{~S}}^{1} \quad$ Per phase rotor current of DFIG and SCIM (referred to stator of DFIG and SCIM), respectively, A 
$N_{\mathrm{RD}}$ and $\quad$ Rotor speed of DFIG and SCIM,

$N_{\mathrm{RS}} \quad$ respectively, $\mathrm{rpm}$

$N_{\mathrm{SD}}$ and $N_{\mathrm{SS}}$ Synchronous speed of DFIG and SCIM, respectively, rpm

$P_{\mathrm{mD}} \quad$ Mechanical power input to DFIG, $\mathrm{kW}$

$P_{\mathrm{mS}} \quad$ Mechanical power input to SCIM/ mechanical power developed from SCIM, $\mathrm{kW}$

$P_{\mathrm{L}}, P_{1 \mathrm{D}}$ and Real power at the PCC from load, DFIG

$P_{1 \mathrm{~S}} \quad$ and SCIM, respectively, $\mathrm{kW}$

$R_{\mathrm{mD}}, R_{\mathrm{mS}} \quad$ Per phase core loss resistance of DFIG and SCIM, respectively, $\Omega$

$R, R_{1 \mathrm{D}}, R_{1 \mathrm{~S}} \quad$ Per phase load and stator winding resistance of DFIG and SCIM, respectively, $\Omega$

$Q_{\mathrm{L}}, Q_{1 \mathrm{D}}$ and Reactive power at the PCC from load,

$Q_{1 \mathrm{~S}} \quad$ DFIG and SCIM, respectively, kVAR

$s_{\mathrm{D}}$ and $s_{\mathrm{S}} \quad$ Operating slip of DFIG and SCIM, respectively

$V_{\mathrm{dc}} \quad$ Battery voltage, $\mathrm{V}$

$V_{\mathrm{PCC}} \quad$ Per-phase voltage at the PCC, V

$V_{2 \mathrm{D}} \quad$ Per-phase rotor voltage, $\mathrm{V}$

$X_{\mathrm{mD}}, X_{\mathrm{mS}} \quad$ Per phase magnetizing reactance of DFIG and SCIM, respectively, $\Omega$

$X, X_{1 \mathrm{D}}, X_{1 \mathrm{~S}} \quad$ Per phase load and stator winding reactance of DFIG and SCIM, respectively, $\Omega$

\section{References}

[1] Renewable Energy Policy Network for the 21st Century 2015 Renewables 2014 global status report. URL: http://www. ren21.net

[2] Global Wind Energy Council 2015 Global wind statistics. URL: http://www.gwec.net

[3] Alnasir Z and Kazerani M 2013 An analytical literature review of stand-alone wind energy conversion systems from generator viewpoint. Renew. Sustain. Energy Rev. 28: 597-615

[4] Blaabjerg F and Ma K 2013 Future on power electronics for wind turbine systems. IEEE J. Emerg. Sel. Top. Power Electron. 1(3): 139-152

[5] Liserre M, Cardenas R, Molinas M and Rodriguez J 2011 Overview of multi-MW wind turbines and wind parks. IEEE Trans. Ind. Electron. 58(4): 1081-1095

[6] Orlando N A, Liserre M, Mastromauro R A and Dell'Aquila A 2013 A survey of control issues in PMSG-based small wind-turbine systems. IEEE Trans. Ind. Informat. 9(3): 1211-1221

[7] Tazil M, Kumar V, Bansal R C, Kong S, Dong Z Y, Freitas W and Mathur H D 2010 Three-phase doubly fed induction generators: an overview. IET Electr. Power Appl. 4(2): 75-89

[8] Agbossou K, Kolhe M, Hamelin J and Bose T K 2004 Performance of a stand-alone renewable energy system based on energy storage as hydrogen. IEEE Trans. Energy Convers. 19(3): 633-640

[9] Cimuca G, Breban S, Radulescu M M, Saudemont C and Robyns B 2010 Design and control strategies of an induction-machine-based flywheel energy storage system associated to a variable-speed wind generator. IEEE Trans. Energy Convers. 25(2): 526-534

[10] Garvey S 2015 Integrating energy storage with renewable energy generation. Wind Eng. 39(2): 129-140

[11] Gyawali N, Ohsawa Y and Yamamoto O 2011 Power management of double-fed induction generator-based wind power system with integrated smart energy storage having superconducting magnetic energy storage/fuel-cell/electrolyser. IET Renew. Power Gener. 5(6): 407-421

[12] Haruni A M O, Negnevitsky M, Haque M E and Gargoom A 2013 Novel operation and control strategy for a standalone hybrid renewable power system. IEEE Trans. Sustain. Energy 4(2): 402-413

[13] Mendis N, Muttaqi K M and Perera S 2014 Management of battery-supercapacitor hybrid energy storage and synchronous condenser for isolated operation of pmsg based variable-speed wind turbine generating systems. IEEE Trans. Smart Grid 5(2): 944-953

[14] Mendis N, Muttaqi K M, Perera S and Kamalasadan S 2015 An effective power management strategy for a wind-dieselhydrogen based remote area power supply system to meet fluctuating demands under generation uncertainty. IEEE Trans. Ind. Appl. 51(2): 1228-1238

[15] Nehrir M H, Wang C, Strunz K, Aki H, Ramakumar R, Bing J, Miao Z and Salameh Z 2011 A review of hybrid renewable/alternative energy systems for electric power generation: configurations, control, and applications. IEEE Trans. Sustain. Energy 2(4): 392-403

[16] Papaefthimiou S, Karamanou E, Papathanassiou S and Papadopoulos M 2009 Operating policies for wind-pumped storage hybrid power stations in island grids. IET Renew. Power Gener. 3(3): 293-307

[17] Papaefthimiou S, Karamanou E, Papathanassiou S and Papadopoulos M 2010 A wind-hydro-pumped storage station leading to high RES penetration in the autonomous island system of Ikaria. IEEE Trans. Sustain. Energy 1(3): 163-172

[18] Senthilkumar S, Kumaresan N, Rakesh N, Vijayakumar K and Subbiah M 2012 Wind-Driven SEIGs for supplying isolated loads employing dsp based power electronic controllers. Wind Eng. 36(6): 739-758

[19] Kaldellis J K, Zafirakis D and Kavadias K 2009 Technoeconomic comparison of energy storage systems for island autonomous electrical networks. Renew. Sustain. Energy Rev. 13: 378-392

[20] Al-Bahrani A H and Malik N H 1993 Voltage control of parallel operated induction generators. IEEE Trans. Energy Convers. 8(2): 236-242

[21] Chakraborty C, Bhadra S N and Chattopadhya A K 1999 Analysis of parallel-operated self-excited induction generators. IEEE Trans. Energy Convers. 14(2): 209-216

[22] Lee C H and Wang L 1998 A novel analysis of parallel operated self-excited induction generators. IEEE Trans. Energy Convers. 13(2): 117-123

[23] Palle B, Simoes M G and Farret F A 2005 Dynamic simulation and analysis of parallel self-excited induction generators for islanded wind farm systems. IEEE Trans. Ind. Appl. 41(4): 1099-1106

[24] Goel P K, Singh B, Murthy S S and Kishore N 2011 Isolated wind-hydro hybrid system using cage generators and battery storage. IEEE Trans. Ind. Electron. 58(4): 1141-1153 
[25] Vijayakumar K, Kumaresan $\mathrm{N}$ and Ammasai Gounden $\mathrm{N}$ 2012 Operation and closed-loop control of wind-driven stand-alone doubly fed induction generators using a single inverter-battery system. IET Electr. Power Appl. 6(3): 162-171

[26] Navin Sam K, Kumaresan N, Ammasai Gounden N and Katyal R 2015 Analysis and control of wind-driven standalone doubly-fed induction generator with reactive power support from stator and rotor side. Wind Eng. 39(1): 97-112
[27] Vijayakumar K, Kumaresan N and Ammasai Gounden N 2013 Operation of inverter-assisted wind-driven slip-ring induction generator for stand-alone power supplies. IET Electr. Power Appl. 7(4): 256-269

[28] Graovac D and Purchel M 2009 IGBT power losses calculation using the data-sheet parameters. Application Note, vol. 1.1

[29] Semikron Electronics Private Limited 2016 SKM300GB125. URL: http://www.semikron.com 